\title{
Multiple Infection of Apple Trees by Distinct Strains of 'Candidatus Phytoplasma mali' and Its Pathological Relevance
}

\author{
Erich Seemüller, Emese Kiss, Sandor Sule, and Bernd Schneider
}

First and fourth authors: Julius Kuehn Institute, Federal Research Centre for Cultivated Plants, Institute for Plant Protection in Fruit Crops and Viticulture, D-69221 Dossenheim, Germany; and second and third authors: Plant Protection Institute of the Hungarian Academy of Science, H-1525 Budapest, Hungary.

Accepted for publication 29 April 2010.

\begin{abstract}
Seemüller, E., Kiss, E., Sule, S., and Schneider, B. 2010. Multiple infection of apple trees by distinct strains of 'Candidatus Phytoplasma mali' and its pathological relevance. Phytopathology 100:863-870.

Forty-eight apple trees infected by 'Candidatus Phytoplasma mali' were examined using single-strand conformation polymorphism (SSCP) and sequence analysis of a variable $h f l B$ gene fragment and the immunodominant membrane protein-encoding imp gene. SSCP analysis of polymerase chain reaction-amplified $h f l B$ gene fragments revealed diverse profiles, differing in number and position of the bands. The ' $\mathrm{Ca}$. P. mali' content of a single infected apple tree was termed an accession. Cloning of fragments from accessions that yielded fewer bands resulted in clone populations showing uniform or moderately polymorphic SSCP patterns and largely homogenous nucleotide sequences. In contrast,

formed two to four distinct groups of profiles. DNA fragments from such accessions were diverse and clustered distantly when subjected to phylogenetic analysis, mostly as two homogenous groups plus one or a few other sequences. Similar results were obtained upon imp gene examination. The collective data indicate that accessions exhibiting more complex patterns were composed of two or three distinct ' $\mathrm{Ca}$. P. mali' strains. There is evidence that multiple infections are of pathological relevance due to strain interactions leading to shifts in the populations. In triply infected trees of one accession, no specific symptoms were induced by the presence of two of the strains. The rare appearance of pronounced symptoms was associated with a separate strain that possessed a unique SSCP profile and a unique $h f l B$ sequence. The two mild strains from this apple accession also induced only mild symptoms on periwinkle and tobacco and occurred specifically in one of these plants.
\end{abstract} inserts from accessions yielding more bands were heterogeneous and
The uncultivated wall-less bacterium 'Candidatus Phytoplasma mali' is the cause of apple proliferation (AP), one of the most important phytoplasmal diseases in Europe. This vector-born disorder induces a range of symptoms that are either specific, such as witches'-brooms, rosettes, and enlarged stipules, or nonspecific, such as foliar reddening, yellowing, growth suppression, and undersized fruit. However, symptom expression is often subject to fluctuation. Witches'-brooms and undersized fruit are typical for newly diseased trees and can often be observed for only one or a few years after they first appear. Then, trees may recover and show no or only mild symptoms for shorter or longer periods $(5,27)$. Symptom development also depends on the virulence of the infecting AP phytoplasma strain. As recently reported, 24 randomly collected apple isolates of ' $C a$. P. mali' differed greatly in aggressiveness when graft inoculated onto healthy apple rootstocks. After 12 years of observation, the accessions (' $\mathrm{Ca}$. P mali' content from a single tree) were classified into three groups: avirulent or mildly virulent, moderately virulent, and strongly virulent. The three groups occurred in approximately the same frequency. Vigor and performance of trees infected by the first group were virtually indistinguishable from healthy controls and showed only occasionally mild symptoms such as enlarged stipules and foliar reddening (29).

On the basis of $16 \mathrm{~S}$ rDNA and 16S-23S rDNA spacer sequences, ' $\mathrm{C}$. $\mathrm{P}$. mali' is a homogenous species throughout Europe (28). However, typing based on restriction fragment length polymorphism (RFLP) analysis of ribosomal protein genes (20)

Corresponding author: E. Seemüller; E-mail address: erich.seemueller@jki.bund.de

doi:10.1094/PHYTO-100-9-0863

(c) 2010 The American Phytopathological Society or on sequences of nonribosomal loci, including the imp, aceF, pnp, and $\sec Y$ genes (7) and a putative nitroreductase gene $(11,12)$, revealed genetic diversity in ' $\mathrm{Ca}$. P. mali'. Also, Southern blot hybridization analysis (14), chromosome size estimation, and RFLP analysis of macrorestriction fragments $(15,28,29)$, and immunological analyses using monoclonal antibodies and polyclonal antisera $(20,28)$, showed molecular variability within this pathogen. Two major subgroups of ' $\mathrm{Ca}$. P. mali', designated AT or AT-1 and AP, have been delineated by Southern blot hybridization and RFLP analysis $(12,14)$. Additional subtypes have been defined by RFLP and sequence analysis of polymerase chain reaction (PCR)-amplified DNA $(11,12,20)$. The occurrence of two different subtypes in a single tree has been reported (20). There is also indication that multiple infections by distinct strains of ' $\mathrm{Ca}$. P. asteris', the aster yellows agent, occur in other crops (33).

Single-strand conformation polymorphism (SSCP) analysis is another tool to study genetic diversity (24). SSCP is the electrophoretic separation of single-stranded nucleic acids based on subtle differences in sequence (often a single base) which results in a different secondary structure and a measurable difference in mobility through a gel (24). Using usually heat-denaturated PCR products, this technique is widely used in other disciplines but only rarely yet in phytoplasmology $(10,23,25)$. An $h f l B$ (or fts $H$ ) gene of ' $\mathrm{Ca}$. P. mali' strain AT proved to be particularly useful for typing of AP phytoplasma isolates (25). $h f l B$ genes encode membrane-associated ATP-dependent $\mathrm{Zn}$ proteases that are conserved among bacteria and are involved in membrane-associated processes such as protein secretion and membrane protein assembly as well as adaptations to nutritional conditions and osmotic stress (2). In most bacteria, $h f l B$ is a single-copy gene whereas, in phytoplasmas, up to 24 copies are present $(1,2)$. In the 
complete sequence of ' $\mathrm{Ca}$. P. mali' strain AT chromosome (accession number CU469464) $12 \mathrm{hflB}$ genes were annotated that belong to several groups of paralogs (15). A variable 528-bp fragment of gene ATP00464 of one of these groups (paralogs are ATP00034, ATP00454, and ATP00457) was selected for analyzing strain variability in ' $C a$. P. mali' by SSCP and sequence analysis. Twenty different patterns were obtained using this sequence (25). In continuing this work, we identified samples with more complex patterns that suggested the presence of multiple infections in a single tree. Based on the $h f l B$ marker, accessions with such patterns were examined in comparison with isolates showing relatively simple patterns.

As a second marker, we included the immunodominant membrane protein (imp) gene of ' $\mathrm{Ca}$. P. mali' in our study $(3,15)$. Imps are encoded by single-copy genes and are supposed to be involved in pathogen-host interactions and, thus, of pathological relevance. The Imps of the AP or $16 \mathrm{SrX}$ phytoplasma group that include, beside the AP agent, ' $C a$. P. pyri', ' $C a$. P. prunorum', ' $C a$. P. spartii', and the phytoplasma associated with peach yellow leaf roll, are classified as a distinct type $(13,22)$. The imp gene is more variable than the taxonomical particularly relevant $16 \mathrm{~S}$ rDNA gene and, thus, has been used to examine genetic variation between and within closely related taxonomic entities of the AP phytoplasma group $(7,22)$.

In this article, we describe, as result of the combined SSCP and sequence analysis of the $h f l B$ gene fragment and the imp gene, the identification of multiple ' $C a$. P. mali' infections in apple and their association with more complex SSCP banding patterns. First findings on the phytopathological relevance of multiple infections are reported.

\section{MATERIALS AND METHODS}

Plant material. Forty-eight ' $C a$. P. mali'-infected apple trees were examined. Root or shoot scions from 13 trees (codes between 1/93 and 17/93), mostly older than 12 years, were collected in Baden-Württemberg (Germany) and Burgundy (France) in 1993. Infectious scions were side grafted onto healthy rootstock M 11, top grafted with healthy cv. Golden Delicious scions, and grown at the Dossenheim institute. Of the accessions studied in more detail, $1 / 93$ and 17/93 were mildly virulent, 10/93 moderately virulent, and 3/93 and 14/93 severely virulent (29). Accessions 1/93 and 17/93 were propagated by grafting and, in addition to the field-grown trees, were also maintained in an unheated greenhouse for 5 years. Twenty-two 10- to 20-year-old Golden Delicious trees (codes 2/4 to 8/7, GDH4, Rol, and WS) were sampled in 2007 at the experimental field of the Dossenheim institute or in Heidelberg, Germany. These accessions were grafted onto healthy $M 11$ rootstocks as described and maintained in an unheated greenhouse. Eleven samples were collected in 2009 from 60- to 80-year-old cider apple trees near Stuttgart (Germany). ' $C a$. P. mali' strains AT (21) and AP15 (6) were used as references and were maintained in the experimental hosts periwinkle (Catharanthus roseus) and tobacco (Nicotiana occidentalis and N. tabaccum cv. Samsun) by periodic grafting in an insect-proof greenhouse. The same applies for accession 1/93 following dodder transmission, first to periwinkle and then to tobacco.

DNA extraction, PCR amplification, and SSCP analysis. Root or the current season's shoot samples were taken from infected apple trees. Shoot samples were collected in late summer or early fall. DNA was extracted from phloem preparations of roots and shoots using a cetyltrimethylammonium bromide (CTAB) procedure (29). The CTAB method was also used to isolate DNA from leaf midribs of periwinkle and tobacco. PCR amplification was performed employing primer pair fHflB3_1/ rHflB3 (5'-TTCTAGCTATTCATCGTGAA-3'/5'-CGGCGCGA TTAGTAGCTCC-3') that specifically amplifies a 528-bp frag- ment of ATP00464 hflB gene homologues (positions 441-968 in strain AT) from all AP phytoplasma strains (25). The imp gene (15) was amplified using primers f318B_seq/r318B_seq (5'AATAATGGAAGCAAATCAAC-3'/5'-GGAGTTCAATTTCA TCCT-3'). Amplification of the imp gene was performed in $25-\mu \mathrm{l}$ reactions containing 5 pmol of each primer, $1 \times$ polymerase buffer, $0.6 \mathrm{U}$ of Taq polymerase (both Invitrogen), and $0.1 \mathrm{mM}$ each dNTP. The reaction was cycled with the following parameters: 5 min of initial denaturation at $95^{\circ} \mathrm{C}$ followed by 35 cycles at $95^{\circ} \mathrm{C}$ for $1 \mathrm{~min}, 52^{\circ} \mathrm{C}$ for $0.45 \mathrm{~min}$, and $70^{\circ} \mathrm{C}$ for $1.5 \mathrm{~min}$. The final step was $5 \mathrm{~min}$ at $70^{\circ} \mathrm{C}$. Polyacrylamide gel electrophoresis and silver staining for SSCP analysis were carried out as reported previously (25).

Real-time (RT)-PCR was carried out using Bio-Rad iCycler IQ. The template was amplified using primer pair fHflB-RT/rHflBRT1 (5'-AAATTAAATGCTCCTTGTGTGTT-3' $/ 5^{\prime}$-ATCACAA TAATACCTTGAGATGG-3'). The two strains of accession 1/93 present in periwinkle and tobacco were specifically detected with Cy5-labeled Taqman probe 1/93-periwinkle (5'-CTAGGTGGT AAAAGAGGTGGT-3') and FAM-labeled probe 1/93-tobacco (5'-TTAGGTGGTCGAAGAGGAGGA-3'), respectively. The PCR reaction mixture contained the following in a final volume of $50 \mu \mathrm{l}$ : $2.5 \mathrm{U}$ of Taq polymerase, $1 \times$ polymerase buffer with $3 \mathrm{mM}$ $\mathrm{MgCl}_{2}$ (both Amplicon), $0.2 \mathrm{mM}$ dNTPs, $0.4 \mu \mathrm{M}$ each primer, $0.2 \mu \mathrm{M}$ each probe, and $5 \mu \mathrm{l}$ of DNA extract. The parameters used for amplification were $5 \mathrm{~min}$ at $95^{\circ} \mathrm{C}$ followed by a two-step protocol consisting of 41 cycles at $95^{\circ} \mathrm{C}$ for $30 \mathrm{~s}$ and $55^{\circ} \mathrm{C}$ for $30 \mathrm{~s}$. The samples were run in duplicates.

Cloning, sequencing, and phylogenetic analysis. PCR products of the $h f l B$ gene fragment and the imp gene were cloned with the pGEM-T Easy vector system (Promega). Following PCR amplification of the inserts of recombinant plasmids and SSCP analysis, selected clones were propagated in Luria-Bertani medium. DNA of recombinant plasmids was extracted with a miniprep kit (Qiagen). PCR-amplified fragments for direct sequencing were purified using the QIAquick PCR purification kit (Qiagen). Cloned fragments were sequenced using M13 forward and reverse primers and PCR products were sequenced using the PCR amplification primers fHflB3_1 and rHflB3 or f318B_seq and r318B_seq. Alignment of sequences was performed with ClustalX (31). Phylogenetic comparison was performed with MEGA4 using parsimony parameters and bootstrap analysis (30).

Nucleotide sequence accession numbers. The sequences of the imp gene were submitted under the accession numbers FN658471 to FN658504 and the $h f l B$ gene fragment sequences under the accession numbers FN658537 to FN658606 at EMBL. The accession numbers of other $h f l B$ sequences used are: FM201256 for 1/93-periwinkle, FM201251 for 14/93-apple, FM201252 for 17/93-apple, FM201248 for AP15-periwinkle, and CU469464 for AT-periwinkle.

\section{RESULTS}

SSCP analysis of PCR-amplified $\boldsymbol{h} f l B$ gene fragments. SSCP analysis of 36 of the 48 accessions revealed two to five bands that were arranged by differences in mobility in one or two groups (Table 1). Such patterns are referred to as less complex profiles. PCR products from the remaining 12 accessions showed more complex profiles that consisted of up to seven bands that were arranged in three groups (Table 1). Examples of the various profile categories are shown in Figure 1A. Accessions with more complex profiles were mostly collected from trees older than 10 years. From the group with more complex profiles, accessions $1 / 93,3 / 93,10 / 93,14 / 93$, and 17/93 were examined in more detail. Of these, accessions 1/93 and 17/93 and accessions 3/93, 10/93, and 14/93 showed similar "full" profiles composed of three groups of bands. However, polymorphisms in the patterns of accessions 1/93, 3/93, 14/93, and 17/93 were observed (Table 1; 
Fig. 1A; and data not shown). These variations consisted of the lack of one or two groups of bands of the full profile and were interpreted as the absence of one genotype of the AP phytoplasma populations represented by the entire patterns. An additional profile was identified in a single root sample of accession 1/93 from a nonsymptomatic field-grown tree (Fig. 1A, 1/93-apple S).

Another indication of the presence of more than one distinct genotype of the AP agent in one tree was found following dodder transmission of accession 1/93 to periwinkle and tobacco. PCR products from these experimental hosts showed distinctly different SSCP patterns. The 1/93 profile observed in periwinkle was identical to the two upper groups of bands occurring in samples from diseased apple whereas the profile from tobacco was identical to the lower group of bands in samples from apple (Fig. 1A). In contrast to accession 1/93, strains AT and AP15 showed the same profile when sampled from periwinkle and tobacco (data not shown).

RT-PCR detection of accession 1/93 phytoplasmas. In all 17 samples from periwinkle plants, 8 samples from tobacco plants, and 7 samples from apple trees all infected by accession 1/93 were examined. In all samples from periwinkle, only the genotype represented by the two upper groups of bands was detected whereas, in all samples from tobacco, only the genotype represented by the lower group was identified. The cycle threshold values in positive samples were 19.8 to 30.8 whereas none of the negative samples displayed fluorescence signals above the threshold line. Thus, the phytoplasma present in tobacco did not occur in periwinkle at a detectable level and vice versa. With the procedure used, both phytoplasmas were detected in DNA samples from six diseased apple trees, simultaneously or separately, depending on the SSCP profile (data not shown).

SSCP analysis of cloned $\boldsymbol{h} \boldsymbol{f l B}$ DNA. To confirm the presence of multiple infections in the trees showing more complex profiles, products of two to four PCR reactions from different DNA samples of accessions 1/93, 3/93, 10/93, 14/93, and 17/93 were cloned. For comparison, products of one to three PCR reactions from eight accessions $(2 / 4,3 / 2,3 / 3,3 / 4,3 / 8,5 / 93$, Rol, and WS) showing one group of bands and eight accessions (3/1, 3/5, 3/6, 8/7, GDH4, 4/93, 6/93, and 9/93) showing two groups of bands were cloned as well. Following PCR amplification of the cloned inserts and SSCP analysis of 8 to 15 clones from each PCR product, homogenous and heterogeneous clone populations were obtained (Table 1). Of the less-complex accessions, only uniform profiles were shown by $2 / 4,3 / 1,3 / 4,3 / 8,4 / 93,5 / 93,9 / 93$, Rol, and WS whereas accessions 3/2,3/3, 3/5, 3/6, 8/7, 6/93, and GDH4 yielded polymorphic profiles (Fig. 1B; accessions $3 / 5$ and $8 / 7$, for example). Cloning of the more complex accessions (1/93, $3 / 93,10 / 93,14 / 93$, and 17/93) resulted mostly in heterogeneous and homogenous populations. SSCP profiles of diverse clones from these accessions are depicted in Figure 1B. In addition to the SSCP profiles of the two mostly predominant genotypes that form the full patterns, one or two other, usually less-frequent profiles

TABLE 1. Single-strand conformation polymorphism (SSCP) characteristics and sequence identity of $h f l B$ gene fragments of single-strain and multiple-strain accessions of 'Candidatus Phytoplasma mali'

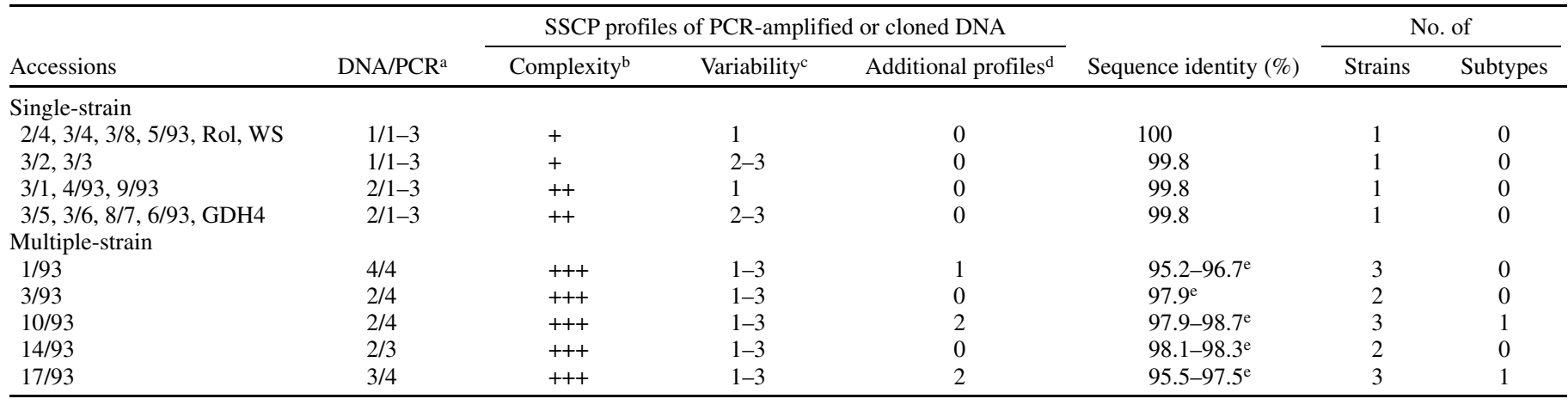

${ }^{\text {a }}$ Number of DNA samples/number of polymerase chain reaction (PCR) products examined.

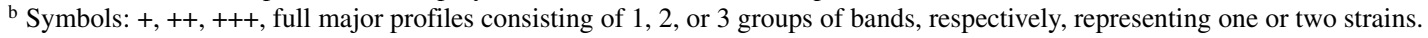

${ }^{c}$ Number of different profiles shown.

${ }^{\mathrm{d}}$ Representing strains or subtypes not included under "Complexity"

${ }^{\mathrm{e}}$ Differences between distinct strains.

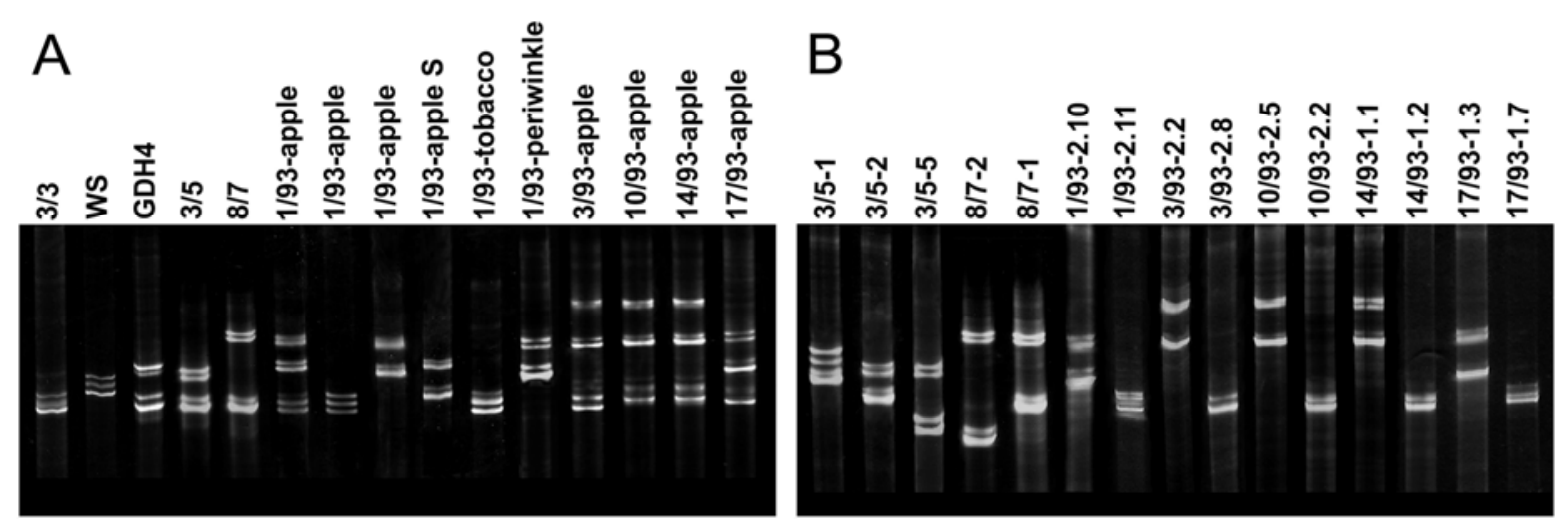

Fig. 1. Single-strand conformation polymorphism profiles of 528-bp $h f l B$ gene fragments of 'Candidatus Phytoplasma mali' accessions. A, Profiles of polymerase chain reaction-amplified fragments. Lanes $3 / 3$ through $8 / 7$, accessions from single strain-infected apple trees. Lanes of accession $1 / 93$, samples from dually infected (lane 6) and singly infected (lanes 7 to 9) apple tissue and singly infected periwinkle and tobacco plants. Lanes 3/93 through 17/93, profiles of accessions showing dual infection in apple. B, Profiles of cloned $h f l B$ gene fragments from infected apple. Lanes 3/5-1 through 8/7-1, profile variations of single-strain accessions 3/5 and 8/7. Lanes 1/93-2.10 through 17/93-1.7, distinctly different profiles of two strains of accessions 1/93, 3/93, 10/93, 14/93, and 17/93, respectively. 
were identified in cloned inserts of accessions 1/93, 10/93, and $17 / 93$ (Table 1). The various profile categories in the clone populations as well as in PCR products of accessions 1/93, 3/93, $10 / 93,14 / 93$, and 17/93 occurred unevenly, indicating an unequal distribution of the various genotypes in infected trees (Table 2).

Sequence analysis of $\boldsymbol{h} \boldsymbol{f l B}$ gene fragments. From 16 accessions, 68 cloned inserts and seven PCR products were sequenced. Related to the SSCP pattern categories, phylogenetic analysis revealed uniform clone populations as well as populations showing minor or major differences in their sequences. All sequences of accessions characterized by one or two groups of bands and uniform SSCP profiles were fully homologous. This applies to accessions 3/4, 3/8,5/93, Rol, and WS, from which two or three clones were sequenced. Accessions characterized by two groups of bands and showing SSCP polymorphisms (3/2, 3/3, 3/5, 8/7, $4 / 93$, and GDH4) showed little sequence variation. Even in the case of distinctly different profiles (Fig. 1B; accessions $3 / 5$ and $8 / 7$, for example), the identity of the inserts was $99.8 \%$, corresponding to the substitution of a single nucleotide. All reads of a given accession always clustered in the same branch of the phylogram (Fig. 2A).

Considerably more genetic variation was observed in the sequences of the five accessions characterized by three groups of bands. Corresponding to the two major groups of SSCP profiles,

TABLE 2. Frequency of single-strand conformation polymorphism profiles of $h f l B$ gene fragments in polymerase chain reaction (PCR)-amplified and cloned DNA representing distinct strains of 'Candidatus Phytoplasma mali' that occur in multiple-strain accessions from infected apple trees

\begin{tabular}{|c|c|c|c|c|c|c|c|}
\hline \multirow[b]{3}{*}{ Accession } & \multicolumn{7}{|c|}{ Profiles representing } \\
\hline & \multirow{2}{*}{$\frac{\text { Two strains }^{\mathrm{a}}}{\text { PCR products }}$} & \multicolumn{2}{|c|}{ One of these strains ${ }^{b}$} & \multicolumn{2}{|c|}{ Second strain ${ }^{c}$} & \multicolumn{2}{|c|}{ Additional strains } \\
\hline & & PCR products & Cloned inserts & PCR products & Cloned inserts & PCR products & Cloned inserts \\
\hline $1 / 93$ & 31 & 16 & 39 & 3 & 21 & $9^{d}$ & $20^{\mathrm{d}}$ \\
\hline $3 / 93$ & 2 & 1 & 3 & 0 & 12 & 0 & 0 \\
\hline $10 / 93$ & 3 & 0 & 11 & 0 & 3 & 0 & $2^{\mathrm{e}}$ \\
\hline $14 / 93$ & 2 & 0 & 2 & 1 & 22 & 0 & 0 \\
\hline $17 / 93$ & 4 & 2 & 5 & 0 & 14 & 0 & $2^{\mathrm{e}}$ \\
\hline
\end{tabular}

a Represented by three groups of bands.

${ }^{\mathrm{b}}$ Represented by the lower group of bands.

${ }^{c}$ Represented by the two upper groups of bands.

${ }^{\mathrm{d}}$ Representing one strain.

e Representing one strain and one subtype.

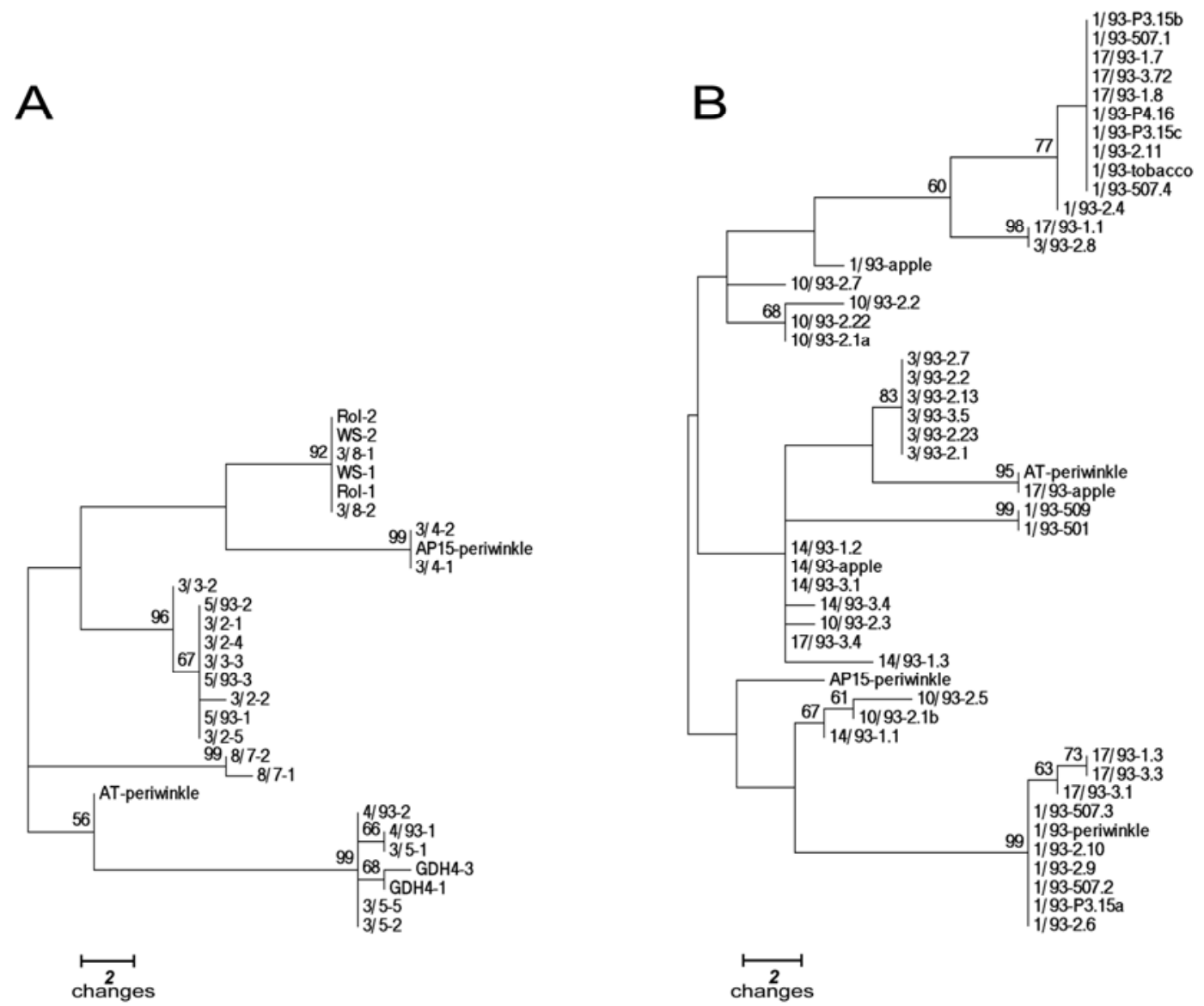

Fig. 2. Phylogenetic diversity of 'Candidatus Phytoplasma mali' accessions based on parsimony analysis of 528-bp hflB gene fragment sequences. A, Phylogram from sequences of accessions from singly infected trees. B, Phylogram from sequences of accessions from trees multiply infected by distinctly different strains. Strains AT and AP15 were used as references. The trees are drawn to scale, with branch lengths calculated using the average pathway method (30). Bootstrap values $>50 \%$ for 1,000 replicates are shown on the branches. Cloned sequences are indicated by an extension of the accession designation showing sample number and clone number. Plant host name extensions indicate sequences of polymerase chain reaction products. 
the sequences of accessions 1/93, 3/93, 10/93, 14/93, and 17/93 clustered distantly in the phylogenetic tree, forming either two distinct groups or distinct groups and distantly clustering single sequences. The distantly clustering sequences differed in 1.5 to $4.8 \%$ of the nucleotide positions (Table 1; Fig. 2B). Because a substantial portion of these values were in the range of ' $\mathrm{Ca}$. $\mathrm{P}$. mali' strains AT and AP15, which share 96.6\% similarity, the distinct genotypes of the five accessions are henceforth referred to as strains. In clone populations of two accessions, additional genotypes were observed that clustered adjacent to distinct strains and showed a lower divergence than distant strains of the same accession. They were designated as subtypes (Table 1).

The sequences of the five accessions showed different clustering characteristics. Accessions 1/93 and 17/93 are closely related. The majority of the reads formed two groups that clustered closely together in the same branch of the two major clades represented by strains AT and AP15 (Table 1; Fig. 2B). The sequences in the two groups were either identical or, with the exception of subtype 17/93-1.1, did not differ in more than one position. The sequence similarity between the groups was, on average, $\approx 96 \%$. In addition to the major groups, there were two sequences of accessions 1/93 (1/93-501 and 1/93-509) and one sequence of $17 / 93$ (17/93-3.4) that clustered distantly from the two major groups. Their distance to the major groups was similar to that between these groups. The PCR-derived sequences 1/93apple and 17/93-apple clustered distantly from the other reads of these accessions, presumably because they were amplified from a mixed phytoplasma population in the trees.

Although the strains of accessions 3/93, 10/93, and 14/93 showed similar SSCP profiles, the corresponding strains are phylogenetically not as closely related as those of accessions 1/93 and 17/93 (Table 1; Fig. 2B). The reads of accession 3/93 clustered exclusively in the AT clade. Five identical reads formed a distinct branch whereas sequence 3/93-2.8 clustered distantly, sharing $97.9 \%$ similarity with them. From accession 14/93, five of six reads clustered in the same branch of the AT clade and showed 99.2 to $100 \%$ identity. In contrast, sequence 14/93-1.1 clustered in the AP clade, sharing $\approx 98.0 \%$ similarity with the other $14 / 93$ reads. The seven sequences of accession 10/93 were more diverse than the reads of the other accessions. Four of them clustered in the upper major subclade of the AT clade and were either identical or shared $99.0 \%$ (10/93-2.7) to $99.6 \%$ sequence similarity. Due to its smaller distance, sequence 10/93-2.7 is considered to represent a subtype. One sequence clustered in the lower subclade of the AT clade. It differed from the reads clustering in the upper major clade in 1.5 to $1.9 \%$ of the positions. The two sequences clustering in the AP clade shared 97.9 to $98.7 \%$ similarity with those clustering in the AT clade. This data on the phylogenetic distance between the heterogeneous sequences of the five accessions and the mostly high sequence similarities within the different groups prove the presence of mixed infections of two or three distinct strains of ' $\mathrm{Ca}$. P. mali' in the same tree.

SSCP analysis of imp gene. Accessions 1/93, 3/93, 10/93, $14 / 93$, and $17 / 93$ were also examined by inspecting the imp gene. PCR products from a total of nine samples of accession 1/93 from apple, periwinkle, and tobacco and two or three samples from apple trees of the other accessions were included in these investigations. Most samples showed similar banding patterns consisting of an upper and a lower portion. Although the upper portion showed slight variations in the profiles, these patterns were unsuitable for strain differentiation and will not be considered by analysis of the imp gene. However, from the lower portion, there was indication that the patterns consisted of two groups of bands (Fig. 3A and B). First, samples of accession 1/93 from periwinkle and tobacco exhibited distinctly different profiles. Corresponding to the $h f l B$ data, the PCR products from infected periwinkle resulted in profiles with the same mobility as the upper part of the profiles from infected apple. In contrast, samples from tobacco showed mobility similar to that of the lower part of the profiles from infected apple. Another indication that the lower portion of the entire imp gene profiles is contributed by two different strains was that, in some PCR samples of accessions 1/93, 14/93, and $17 / 93$, the upper or the lower group of bands was missing (Fig. $3 \mathrm{~B}$ and data not shown). This also corresponds to the observation made in the $h f l B$ gene work.

From each accession, products of several PCR amplifications from usually different DNA samples were cloned. SSCP analysis revealed that 10 of the 16 clone populations obtained were homogenous and showed either the upper or the lower group of bands, corresponding to the patterns of accession 1/93 from periwinkle and tobacco. The six remaining populations were heterogeneous and depicted both types of profiles (Fig. 3A).

Sequence analysis of the imp gene. Twenty-eight cloned imp genes and six full-length PCR products of the gene were sequenced. Phylogenetic analysis revealed that the reads clustered in three major clades, designated I, II, and III (Fig. 4, from bottom). The structure of the tree showed similarity to the $h f l B$ tree in that two major branches (I and III) are represented by the sequences of strains AP15 and 1/93-periwinkle and strains AT and 1/93-tobacco, respectively. A third clade branched from the AT
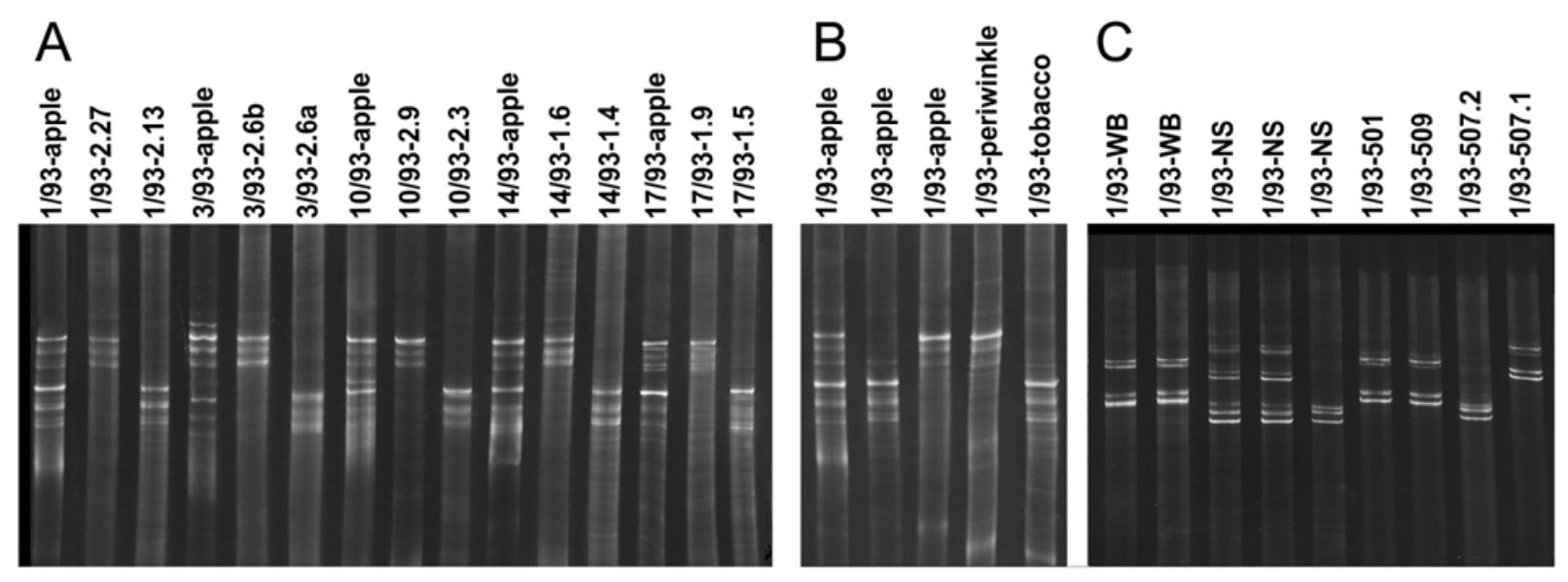

Fig. 3. Single-strand conformation polymorphism profiles of imp genes and hflB gene fragments of 'Candidatus Phytoplasma mali' accessions. A, Profiles of polymerase chain reaction (PCR)-amplified imp genes showing dual infections and cloned imp genes showing single infection by distinctly different genotypes of accessions 1/93 through 17/93 on apple. B, Variation of imp gene profiles of accession 1/93 from infected apple, periwinkle, and tobacco. C, Profiles of PCRamplified or cloned $h f l B$ gene fragments of accession 1/93 from symptomatic (WB, 501, and 509) and nonsymptomatic (NS, 507.1, and 507.2) apple shoots. Cloned sequences are indicated by an extension of the accession designation showing sample number and clone number. Plant host name extensions and extensions WB and NS indicate sequences of PCR products. 
clade and consisted of reads of accessions 10/93 and 14/93. The accessions clustered in two or three clades: 1/93, 3/93, and 17/93 in clades I and III; 10/93 in clades I and II; and 14/93 in all three clades. Within the clades, the sequences were more homogenous than the $h f l B$ sequences, being either identical or showing, with the exception of 1/93-2.27, at least $99.6 \%$ identity. However, the genetic distance of the imp gene sequences clustering at the different branches was considerably higher, as expressed by similarity values of 83.2 to $90.1 \%$. As in the case of the $h f l B$ sequences, these values were in the range of that between strains AT and AP15, which was $86.5 \%$. The high phylogenetic distances between the reads of different groups of the five accessions confirm the finding obtained with $h f l B$ sequences that these accessions represent multiple infections.

Relationship of $\boldsymbol{h f l B}$ gene sequences to virulence of accession 1/93 strains. Over a 13-year period of growth at Dossenheim, the two trees inoculated with accession 1/93 showed occasionally mild symptoms such as enlarged stipules or foliar reddening during the first 6 years and then were devoid of symptoms thereafter. Thus, this accession was classified as mildly virulent (29). In addition, the five trees inoculated with this source and maintained in the greenhouse responded similarly to infection. DNA samples collected between 2005 and 2008 from roots and shoots of the field-grown trees yielded PCR-amplified $h f l B$ gene fragments that showed the two predominant features of 1/93 SSCP profiles, consisting of a lower or two upper groups of bands. Only one root sample collected in 2008 showed a third component of the 1/93 profiles (Fig. 1A, 1/93-apple S). However,

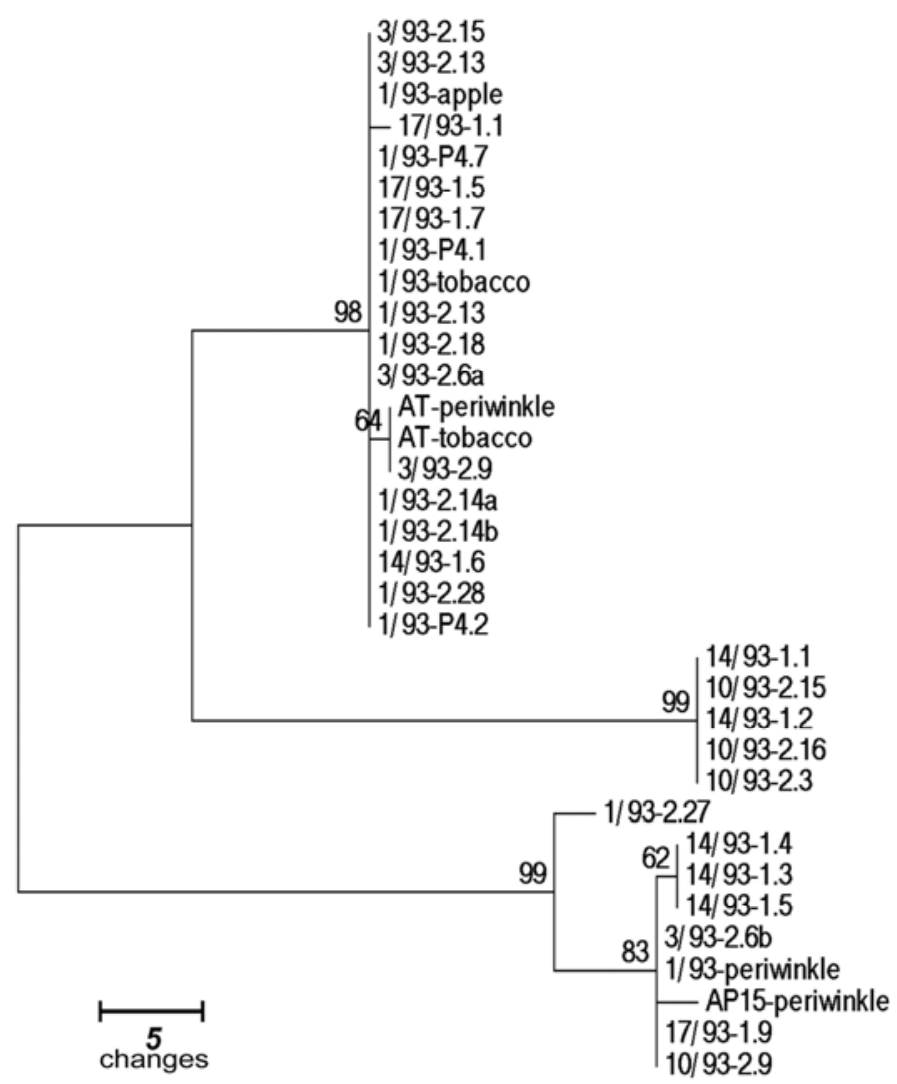

Fig. 4. Phylogenetic diversity of 'Candidatus Phytoplasma mali' accessions based on parsimony analysis of polymerase chain reaction (PCR)-amplified or cloned imp gene sequences of accessions from multiply infected apple trees. Strains AT and AP15 were used as references. The tree is drawn to scale, with branch lengths calculated using the average pathway method (30). Bootstrap values for 1,000 replicates are shown on the branches. Cloned sequences are indicated by an extension of accession designation showing sample number and clone number. Plant host name extensions indicate sequences of PCR products. in 2009, one of the field-grown trees, which was vigorously pruned in the previous dormant season, and one descendant tree in the greenhouse developed witches'-brooms as a severe symptom. SSCP analysis of PCR-amplified $h f l B$ gene fragments from four witches'-brooms and four neighboring shoots exhibiting enlarged stipules resulted in the same unique profile as the root sample. In contrast, samples from 11 shoots collected from nonsymptomatic parts of the field-grown tree showed only the elements of the two predominant strains (Fig. 3C; Table 2).

PCR products from one witches'-broom and one shoot with enlarged stipules were cloned, together with a PCR product from a nonsymptomatic shoot of the same tree. All 20 clones derived from the symptomatic shoots showed the same unique profile whereas the clones derived from the nonsymptomatic shoot showed either the lower or the two upper groups of bands of accession 1/93 (Fig. 3C; Table 2). The two sequences obtained from the symptomatic shoots (1/93-501 and 1/93-509) had a unique position in the phylogenetic tree, indicating a distinct strain status. In contrast, the sequences from the nonsymptomatic shoot (1/93-507.1-4) clustered with the two major groups of 1/93 sequences (Fig. 2B). These data indicate that the strain represented by the sequences 1/93-501 and 1/93-509 is highly virulent whereas the other two groups of sequences are associated with mild strains. This is supported by the fact that these strains, compared with strains AT and AP15, induce only very mild symptoms in periwinkle and tobacco, respectively.

\section{DISCUSSION}

There are several reports on the occurrence of different phytoplasma taxa in a single host plant $(8,18,19)$. These findings include temperate fruit trees. However, information on natural infection of a single plant by different strains or types of the same phytoplasma is sparse. In this study, we used a high-resolution approach mainly based on SSCP and sequence analysis of a variable fragment of an $h f l B$ gene of ' $C a$. P. mali'. With this combination, a detailed differentiation of ' $\mathrm{Ca}$. P. mali' isolates has been achieved (25). All isolates examined in the previous work showed less complex SSCP profiles. In continuing this research, we identified isolates with more complex profiles. These findings include accessions 1/93, 14/93, and 17/93 that previously were described to be associated with less complex patterns (25). Because we identified different profiles by examining several samples and clone populations, these differences can most likely be explained by an uneven distribution of the components of mixed AP phytoplasma populations. Thus, we presumed that accessions showing more complex profiles represent multiple infections. This assumption was verified by comparative analysis of cloned $h f l B$ gene fragments from accessions showing less complex and more complex profiles. The phylogenetic distance of diverse sequences of accessions exhibiting more complex profiles was often in the range of that of reference strains AT and AP15; therefore, it can be concluded that such accessions are composed of two or three different strains. In addition, variants with smaller phylogenetic differences were observed.

To ascertain that the $h f l B$ data were not impaired by an unknown cross reactivity of the primers used with paralogous $h f l B$ genes of ' $C a$. P. mali', we included the single-copy imp gene in our study. Although the often quite uniform SSCP profiles of PCR products of the imp gene did not allow strain differentiation, missing groups of bands in samples from infected apple were indicative for mixed infections. Confirmation of the $h f l B$ results was also obtained by the observation of different profiles of accession 1/93 from periwinkle and tobacco and two groups of SSCP profiles in clone populations. Phylogenetic analysis revealed that the sequences of inserts with diverse profiles of each accession cluster distantly in two or three different major clades. 
Singly and multiply infected trees often have a different history. The 22 accessions from 10- to 20-year-old trees (codes 2/4 to 8/7, GDH4, Rol, and WS) were all collected in well-kept dessert apple orchards. Cloned $h f l B$ gene fragments of such accessions showed no or only minor diversity in SSCP and sequence analysis. In contrast, trees in which multiple infections were identified were mostly older and often grown in less intensively managed orchards. Under such conditions, it is plausible that trees were more frequently exposed to vectors and there was no treatment to control them. Such circumstances increase the changes of trees sustaining multiple infections.

From our results, there is indication that multiple infections are of phytopathological relevance. An interesting aspect is the finding that different strains of accession 1/93 occur in periwinkle and tobacco. In each of these hosts, only one component of the $1 / 93$ complex was detected although a sensitive RT-PCR assay was employed. However, this approach was probably still not sensitive enough because accession $1 / 93$ was transmitted to tobacco via dodder (Cuscuta sp.) bridges from periwinkle in 2000 , after being maintained in this host for more than 1 year. Therefore, it is likely that low phytoplasma numbers of the strain that developed in tobacco survived in periwinkle. There are several possibilities to explain the specific growth in the two hosts. It is possible that the Cuscuta vector preferentially transmitted one strain. The phenomenon may also be explained by host preference of the phytoplasmas. Another, more likely possibility is that the two strains show a different fitness in the two hosts that may result in suppression of one strain by the other. From ongoing work, there is indication that the periwinkle-specific 1/93 strain suppresses strain AT in periwinkle to an undetectable level (E. Seemüller, unpublished observation). It is conceivable that such an interaction may also take place between strains of accession 1/93. Antagonistic suppression between aster yellows phytoplasma strains has repeatedly been reported in early work $(9,16,32)$. Also, difficulties in detecting suppressed strains by leafhopper feeding transmission have been described (9).

Not less interesting than the presumable host-depending suppression of $1 / 93$ strains is the identification of a severe strain in this "mild" accession that was collected in 1993 in Burgundy (France) from an old tree showing enlarged stipules as a specific symptom (29). After growing largely nonsymptomatic at the Dossenheim institute for 13 years, two descendents of the source tree, one grown in the field and the other in the greenhouse, developed witches'-brooms as a severe symptom. This unexpected symptom appearance was associated with a specific SSCP profile and a unique $h f l B$ sequence. One year prior to this finding, a single profile identical to that later found in symptomatic shoots was obtained with DNA from a single root of the previously nonsymptomatic field-grown tree. From this, it is conceivable that the severe variant was latently present in accession 1/93 for a long time, probably as far back as the source tree that showed mild specific symptoms. Formation of witches'-brooms by the fieldgrown tree may have been induced by the growing conditions, most likely by its heavy pruning in the previous dormant season. It is well established that such a measure enormously enhances witches'-broom formation (17). On the other hand, witches'broom formation on the greenhouse-grown tree may have been favored by the higher temperature in the greenhouse than in the field, because several comparable trees infected by accession 1/93 did not develop any symptom when grown in the open (unpublished data).

Knowledge of the simultaneous presence of ' $\mathrm{Ca}$. P. mali' strains with different pathological and other biological traits and their possible interaction may help to shed light upon other poorly understood aspects of AP and probably other phytoplasmoses. One of the phenomena of AP is that severe symptoms, in particular witches'-brooms, occur quite frequently at the onset of disease. Then, the trees often start to recover and may remain nonsymptomatic for shorter or longer periods, after which the disease may or may not reappear, as described above for trees infected by accession 1/93 phytoplasmas. During the remission period, the pathogens are always present in the roots. However, in the aerial parts, ' $\mathrm{Ca}$. P. mali' is either difficult to detect or is present in high numbers $(5,27,29)$. One explanation of remission, reappearance of disease, and the colonization behavior described may be interactions among mixed phytoplasma populations. Such interactions may lead to suppression or stimulation of system components such as avirulent, mild, or severe strains. Interactions in mixed phytoplasma populations may also be responsible for the phenomenon of trees which never showed clear AP symptoms although they were heavily colonized in the roots $(4,29)$. This may be due to the presence of an avirulent strain alone or to the cross-protection activity of such a strain as reported above for the periwinkle-specific 1/93 strain. Strain interactions may also be involved in the phenomenon of older trees that are frequently multiply infected (this article) and often nonsymptomatic or show only mild symptoms (26; unpublished observations). These examples indicate that multiple infections are likely an important factor in appearance and severity of AP.

\section{ACKNOWLEDGMENTS}

This work was supported as part of the SMAP project by the IASMA Research Center at S. Michele all'Adige and the Autonomous Province of Trento (Italy). We thank M. Kampmann and M. Andrasi for technical assistance and F. Hergenhahn for growing plants and maintaining phytoplasma strains.

\section{LITERATURE CITED}

1. Arashida, R., Kakizawa, S., Ishii, Y., Hoshi, A., Jung, H. Y., Kagiwada, S., Yamaji, Y., Oshima, K., and Namba, S. 2008. Cloning and characterization of the antigenic membrane protein (Amp) gene and in situ detection of Amp from malformed flowers infected with Japanese hydrangea phyllody phytoplasma. Phytopathology 98:769-775.

2. Bai, X., Zhang, J. H., Ewing, A., Miller, S. A., Radek, A. J., Shevchenko, D. V., Tsukerman, K., Walunas, T., Lapidus, A., Campbell, J. W., and Hogenhout, S. A. 2006. Living with genome instability: the adaptation of phytoplasmas to diverse environments of their insect and plant hosts. J. Bacteriol. 188:3682-3696.

3. Berg, M., Davies, D. L., Clark, M. F., Vetten, H. J., Maier, G., Marcone, C., and Seemüller, E. 1999. Isolation of the gene encoding an immunodominant membrane protein of the apple proliferation phytoplasma, and expression and characterization of the gene product. Microbiology 145:1937-1943.

4. Bisognin, C., Schneider, B., Salm, H., Grando, M. S., Jarausch, W., Moll, E., and Seemüller, E. 2008. Apple proliferation resistance in apomictic rootstocks and its relationship to phytoplasma concentration and simple sequence repeat genotypes. Phytopathology 98:153-158.

5. Carraro, L., Ermacora, P., Loi, N., and Osler, R. 2004. The recovery phenomenon in apple proliferation-infected apple trees. J. Plant Pathol. 86:141-146.

6. Carraro, L., Osler, R., Refatti, E., and Poggi Pollini, C. 1988. Transmission of the possible agent of apple proliferation to Vinca rosea by dodder. Riv. Patol. Veg. Ser. 4, 24:43-52.

7. Danet, J. L., Bonnet, P., Jarausch, W., Carraro, L., Skoric, D., Labonne, G., and Foissac, X. 2007. Imp and secY, two new markers for MLST (multilocus sequence typing) in the $16 \mathrm{SrX}$ phytoplasma taxonomic group. Bull. Insectol. 60:339-340.

8. Del Serrone, P., La Starza, S., Krystai, L., Kolber, M., and Barba, M. 1998. Occurrence of apple proliferation and pear decline phytoplasmas in diseased pear trees in Hungary. J. Plant Pathol. 80:53-58.

9. Freitag, J. H. 1964. Interaction and mutual suppression among three strains of aster yellows virus. Virology 24:401-413.

10. Han, S., and Cha, B. 2002. Genetic differentiation of phytoplasma isolates by DNA heteroduplex mobility assays and single-strand conformation polymorphism analysis. Plant Pathol. J. 18:308-312.

11. Jarausch, W., Saillard, C., Dosba, F., and Bové, J. M. 1994. Differentiation of mycoplasmalike organisms (MLOs) in European fruit trees by PCR using specific primers derived from the sequence of a chromosomal fragment of the apple proliferation MLO. Appl. Environ. Microbiol. 60:2916-2923.

12. Jarausch, W., Saillard, C., Helliot, B., Garnier, M., and Dosba, F. 2000. 
Genetic variability of apple proliferation phytoplasmas as determined by PCR-RFLP and sequencing of a non-ribosomal fragment. Mol. Cell. Probes 14:17-24.

13. Kakizawa, S., Oshima, K., Ishii, Y., Hoshi, A., Maejima, K., Jung, H. Y., Yamaji, Y., and Namba, S. 2009. Cloning of immunodominant membrane protein genes of phytoplasmas and their in planta expression. FEMS Microbiol. Lett. 293:92-101.

14. Kison, H., Schneider, B., and Seemüller, E. 1994. Restriction fragment length polymorphism within the apple proliferation mycoplasmalike organism. J. Phytopathol. 141:395-401.

15. Kube, M., Schneider, B. Kuhl, H., Dandekar, T., Heitmann, K., Migdoll, A. M., Reinhardt, R., and Seemüller, E. 2008. The linear chromosome of the plant-pathogenic mycoplasma 'Candidatus Phytoplasma mali'. BMC Genomics 9:306.

16. Kunkel, L. O. 1955. Cross protection between strains of aster yellows. Adv. Virus Res. 3:251-273.

17. Kunze, L. 1989. Apple proliferation. Pages 99-113 in: Virus and Viruslike Diseases of Pome Fruits and Simulating Noninfectious Disorders. P. R. Fridlund, ed. Cooperative Extension College of Agriculture and Home Economics, Washington State University, Pullmann.

18. Lee, I.-M., Bertaccini, A., Vibio, M., and Gundersen, D. E. 1995. Detection of multiple phytoplasmas in perennial fruit trees with decline symptoms in Italy. Phytopathology 85:728-735.

19. Lee, I.-M., Gundersen, D. E., Hammond, R. W., and Davis, R. E. 1994. Use of mycoplasmalike organism (MLO) group-specific oligonucleotide primers for nested-PCR assays to detect mixed-MLO infections in a single host plant. Phytopathology 84:559-566.

20. Martini, M., Ermacora, P., Falginella, L., Loi, N., and Carraro, L. 2008. Molecular differentiation of 'Candidatus Phytoplasma mali' and its spreading in Friuli Venezia Giulia region (North-East Italy). Acta Hortic. 395-402.

21. Marwitz, R., Petzold, H., and Özel, M. 1974. Untersuchungen zur Übertragbarkeit des möglichen Erregers der Triebsucht des Apfels auf einen krautigen Wirt. Phytopathol. Z. 81:85-91.

22. Morton, A., Davies, D. L., Blomquist, C. L., and Barbara, D. J. 2003. Characterization of homologues of the apple proliferation immunodominant membrane protein gene from three related phytoplasmas. Mol. Plant Pathol. 4:109-114.
23. Music, M. S., Krajacic, M., and Skoric, D. 2008. The use of SSCP analysis in the assessment of phytoplasma gene variability. J. Microbiol. Methods 73:69-72.

24. Orita, M., Iwahana, H., Kanazawa, H., Hayashi, K., and Sekiya, T. 1989. Detection of polymorphisms of human DNA by gel-electrophoresis as single-strand conformation polymorphisms. Proc. Natl. Acad. Sci. USA 86:2766-2770.

25. Schneider, B., and Seemüller, E. 2009. Strain differentiation of Candidatus Phytoplasma mali by SSCP and sequence analyses of the $h f l B$ gene. J. Plant Pathol. 91:103-112.

26. Seemüller, E., Kison, H., and Lorenz, K.-H. 1998. On the geographic distribution and prevalence of the apple proliferation phytoplasma in lowintensity orchards in Germany. J. Plant Dis. Prot. 105:404-410.

27. Seemüller, E., Kunze, L., and Schaper, U. 1984. Colonization behavior of MLO, and symptom expression of proliferation-diseased apple trees and decline-diseased pear trees over a period of several years. Z. Pflanzenkrankh. Pflanzenchutz 91:525-532.

28. Seemüller, E., and Schneider, B. 2004. 'Candidatus Phytoplasma mali', 'Candidatus Phytoplasma pyri' and 'Candidatus Phytoplasma prunorum', the causal agents of apple proliferation, pear decline and European stone fruit yellows, respectively. Int. J. Syst. Evol. Microbiol. 54:1217-1226

29. Seemüller, E., and Schneider, B. 2007. Differences in virulence and genomic features of strains of 'Candidatus Phytoplasma mali', the apple proliferation agent. Phytopathology 97:964-970.

30. Tamura, K., Dudley, J., Nei, M., and Kumar, S. 2007. MEGA4: Molecular evolutionary genetics analysis (MEGA) software version 4.0. Mol. Biol. Evol. 24:1596-1599.

31. Thompson, J. D., Gibson, T. J., Plewniak, F., Jeanmougin, F., and Higgins, D. G. 1997. The ClustalX windows interface: flexible strategies for multiple sequence alignment aided by quality analysis tools. Nucleic Acids Res. 24:4876-4882.

32. Valenta, V. 1959. Interference studies with yellows-type plant viruses: Cross protection tests with European viruses. Acta Virol. (Prague) 3:6572.

33. Zhang, J. H., Hogenhout, S. A., Nault, L. R., Hoy, C. W., and Miller, S. A. 2004. Molecular and symptom analyses of phytoplasma strains from lettuce reveal a diverse population. Phytopathology 94:842-849. 